\title{
Low-Grade Rhabdoid Meningioma: Unusual Morphological Characteristics
}

\author{
Arvids Jakovlevs*, Andrejs Vanags**, Janis Gardovskis**, Ilze Strumfa* \\ * Department of Pathology, Riga Stradins university \\ ** Department of Surgery, Riga Stradins University, Riga, Latvia
}

\begin{abstract}
Summary
Rhabdoid meningioma (RM) is a rare type of meningioma. It is classified as a grade III tumour (anaplastic meningioma) in the recent World Health Organization (WHO) classification of the tumours of the central nervous system (CNS). Here we describe a unique case of RM lacking any features of malignancy. Few cases of low-grade RMs are described in the literature in contrast with the grading of this entity in WHO classification.
\end{abstract}

Key words: meningioma, rhabdoid, low-grade.

\section{AIM OF THE DEMONSTRATION}

The aim of our article is to report a case of unusual RM lacking malignant features in regard to the issue about the prognostic significance of rhabdoid morphology in meningiomas.

\section{CASE REPORT}

A 37-year-old woman was admitted to the hospital due to progressive headaches over previous 1.5 years. The magnetic resonance imaging of head and brain revealed a well-demarcated intracranial lesion measuring $3.5 \times 3.6 \times 3.6 \mathrm{~cm}$ (Figure 1A). The mass was located adjacent to the frontal bone and was attached to the dura mater. The patient underwent a craniotomy and total tumour resection. Histological examination of the neoplasm revealed cells consistent with rhabdoid morphology. The tumour was almost entirely composed of polygonal, rather large cells that possessed eccentric nuclei, strongly eosinophilic cytoplasm with abundant pale globular inclusions and prominent cytoplasmic granularity (Figure 1B). The nuclei of neoplastic cells were slightly pleomorphic. Mitoses were absent in the whole specimen. In addition, the tumour had well-developed fibrous capsule that demarcated it from normal brain tissues. Psammoma bodies were found in some areas of the tumour. Immunohistochemical visualization (IHC) showed intense cytoplasmic expression of vimentin and epithelial membrane antigen (Figure 1C-D) as well as strong nuclear expression of progesterone receptors in the tumour cells. The neoplastic cells did not express smooth muscle actin, desmin, HMB-45, S-100 protein, kappa and lambda light chains. Ki-67 proliferation index was as low as $1.5 \%$.

Thus, the morphological appearance and immunohistochemical features were consistent with RM and low-grade cellular characteristics.

\section{DISCUSSION}

Tumours with rhabdoid morphology were first described in 1978 in relation to malignant renal tumours of children (1). Nowadays, many tumours with rhabdoid morphology are known in different localizations including CNS and meninges. Rhabdoid cells have no evidence of myogenic origin. The term "rhabdoid" is used to denote close histological resemblance of tumour cells to rhabdomyoblasts. Rhabdoid cells are characterized by typical light microscopic morphology: round cells with eccentric, vesicular nuclei, prominent nucleoli and eosinophilic cytoplasm with paranuclear globular inclusions (3).

Meningiomas developing from the meninges are among the most common intracranial tumours. Regarding these tumours, surgery is the mainstay of treatment, and neurosurgeon also is involved in the planning of further observation and treatment in accordance to the tumour grade (5). Meningiomas show wide range of histopathological appearances. While the majority of meningiomas are benign tumours (WHO grade I meningiomas), some meningiomas have increased risk of local recurrences (WHO grade II meningiomas) and the minority are truly malignant and have a risk of metastatic dissemination; these are classified as WHO grade III meningiomas (2). RM is an uncommon type of meningioma which was described for the first time in 1998 (3). It was found that rhabdoid morphology in meningiomas was associated with a worse prognosis (3). Soon after this finding RM was separated as a distinct entity in WHO classification of CNS tumours published in 2000. RM has been classified as a grade III neoplasm by WHO (2). Consistent with the malignant behaviour, significant mitotic activity, anaplasia and other atypical features are usually found in RMs $(2,4)$. However, there are some isolated reports of RMs with no evidence of 

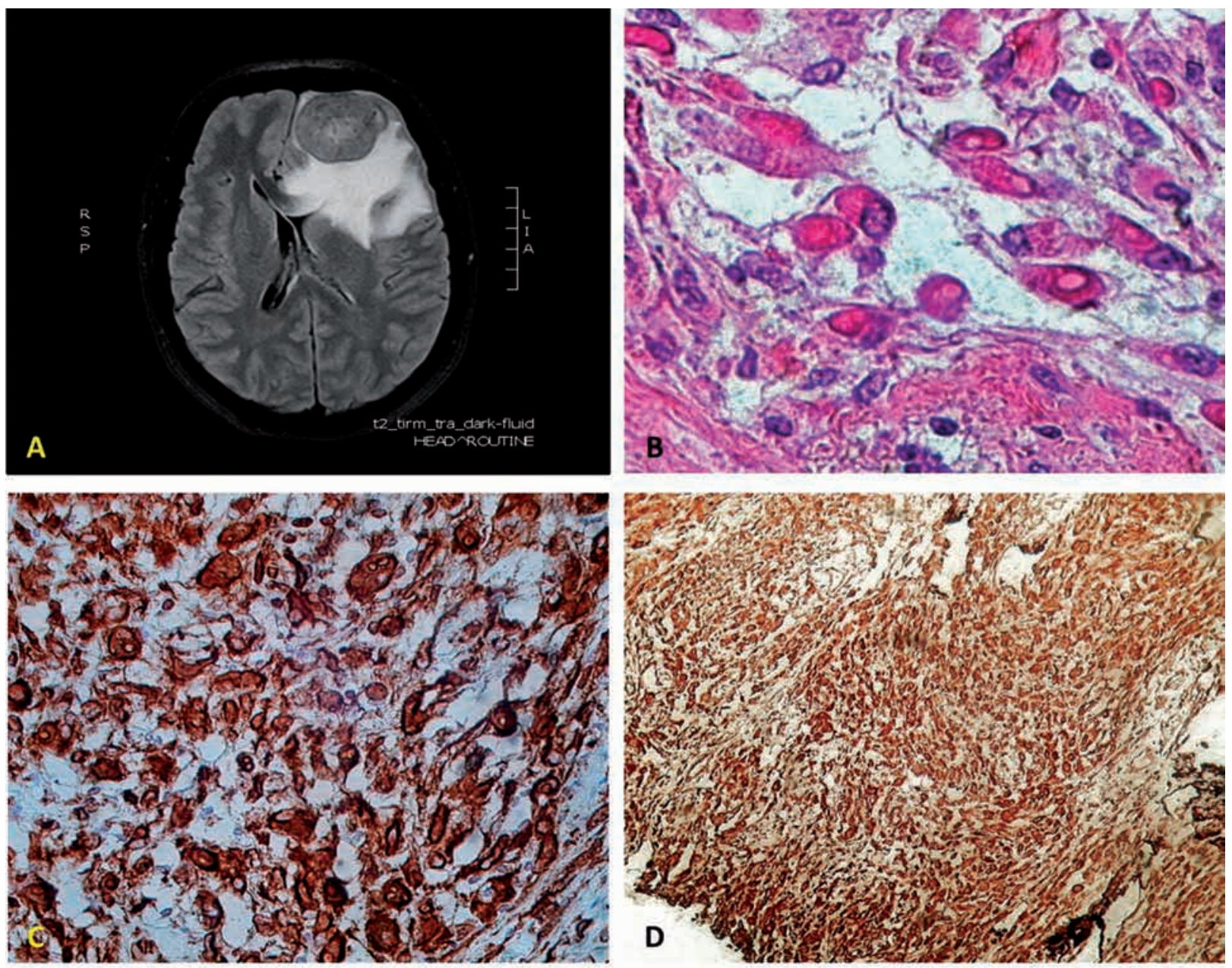

Fig.1. Radiological and pathomorphological features of rhabdoid meningioma. A. Magnetic resonance imaging of head and brain. B. Rhabdoid morphology of the tumour cells. Haematoxylin-eosin, original magnification (OM) $1000 \mathrm{x}$. C. Strong vimentin expression in the tumour cells. Immunoperoxidase, antivimentin, OM $200 \mathrm{x}$. D. Strong expression of epithelial membrane antigen (EMA) in the tumour cells. Immunoperoxidase, anti-EMA, OM $200 \mathrm{x}$

cellular atypia (6). In our case diagnosis of RM was established due to pure rhabdoid morphology along with meningothelial origin that was clearly demonstrated by IHC. Absence of atypia in the tumour cells and low Ki67 proliferation index was consistent with low-grade meningioma in the present case.

In conclusion, rhabdoid meningioma occasionally lacks histological features of malignancy that can lead to confusion if the rhabdoid morphology is always associated with malignant behaviour. Increased awareness of low-grade rhabdoid meningiomas is necessary to estimate the prognosis and to plan the treatment appropriately.
Conflict of interest: None

\section{REFERENCES}

1. Beckwith JB, Palmer NF. Histopathology and prognosis of Wilms tumors: results from the First National Wilms' Tumor Study // Cancer, 1978; 41:1937 - 1948

2. Cooper WA, Shingde M, Lee VK, Allan RS, Wills EJ, Harper C. "Rhabdoid meningioma" lacking malignant features. Report of two cases // Clin Neuropathol, 2004; 23(1):16-20

3. Louis DN, Ohgaki H, Wiestler OD, Cavenee WK Meningeal tumors // In: Bosman FT, Jaffe ES, Lakhani RS, Ohgaki H. WHO Classification of tumours of the central nervous system. $4^{\text {th }}$ edition. Lyon: IARC; 2007; 164-180 
4. Perry A, Scheithauer BW, Stafford SL, Abell-Aleff PC, Meyer FB. Rhabdoid meningioma: an aggressive variant // Am J Surg Pathol, 1998; 22:1482 - 1490

5. Walcott BP, Nahed BV, Brastianos PK, Loeffler JS. Radiation treatment for WHO grade II and III meningiomas // Front Oncol, 2013; 3:227, doi:10.3389/fonc.2013.00227

6. Zhou Y, Xie Q, Gong Y, Mao Y, Zhong P, Che X, Jiang C, Huang F, Zheng K, Li S, Gu Y, Bao W, Yang B, Wu J, Wang Y, Chen H, Xie L, Zheng M, Tang H. Clinicopathological analysis of rhabdoid meningiomas: Report of 12 cases and a systematic review of the literature // World Neurosurg, 2013; $79(5-6): 724-732$

Adress: Arvids Jakovlevs

Department of Pathology, Riga Stradins University Dzirciema Street 16, Riga, LV-1007, Latvia

E-mail: Arvids.Jakovlevs@rsu.lv 